\title{
Consent is Sexy When it is Peer to Peer
}

\author{
Allison Wills, Counsellor/Social Worker \\ David Duncan, Student Health Coordinator \\ Student Wellbeing \\ University of the Sunshine Coast
}

\begin{abstract}
The release of the 'Respect. Now. Always.' survey results on sexual harassment and sexual assault at Australian universities highlighted the need to help students navigate issues related to sexual consent. The Student Wellbeing service at the University of the Sunshine Coast launched a health promotion campaign to address this need. 'Consent is Sexy' is a peer to peer mentoring campaign designed to increase students' knowledge and confidence in asserting their sexual rights. Trained student ambassadors lead the campaign to engage in open conversations with their peers on what consent is and is not. Findings from the 'Consent is Sexy' ambassador training workshops showed the students had increased knowledge of sexual consent and respect, and that the students were comfortable talking to their peers about these issues. The 'Consent is Sexy' campaign is promoted at organised wellbeing events and whenever ambassadors wear their distinctive t-shirts around campus.
\end{abstract}

\section{Background}

The University of the Sunshine Coast (USC) is dedicated to developing and delivering best practice education and training opportunities and preventative campaigns to contribute to ongoing cultural change. In 2017, our commitment to these campaigns and connection to other universities was renewed through the Respect. Now. Always. campaign. We have focused on establishing a governance framework for responding to matters related specifically to sexual harassment and assault. A 'Safer Community Model' has been adopted to develop safety programs, community interventions and to build collaborative partnerships both within USC and with relevant external agencies. Peer to peer mentoring opportunities are a part of our Safer Community Model.

\section{Consent is Sexy}

An example of our peer to peer mentoring initiatives is Consent is Sexy (CIS). This public awareness health promotion campaign led by trained student ambassadors promotes the principles of responsible and respectful behaviour for staff, students and visitors (www.consentissexy.net). CIS provides a platform to further develop our suite of health and wellbeing education, training and ongoing leadership opportunities for students as peer mentors.

The CIS campaign is a peer to peer based campaign promoting the practice of respect, consent and open discussion; responsible, safer sex; sexual health and emotional wellbeing; and gender equality and equality of rights in relationships. Furthermore, the campaign promotes conversations between peers relating to matters of interpersonal and relationship abuse, sexual assault, intimate partner rape, acquaintance or date rape, gender discrimination and homophobia.

USC Student Wellbeing obtained permission from the copyright owners of the Consent is Sexy campaign, which has been implemented in universities and colleges throughout North America, Europe and Africa (www.consentissexy.net). The campaign was chosen as a novel way to engage students, due to its provocative title, vibrant marketing materials and clear messages of consent, respect and safety. Student Wellbeing worked with a project team of four health promotion students who completed an implementation project as part of course-based assessment in a third-year public health course in Semester 1, 2017.

The CIS campaign is part of the USC Student Wellbeing Service's response to the Universities 
Australia's Respect. Now. Always. (RNA) campaign promoted by USC in 2016 and relaunched in 2017. The CIS campaign was initiated to have student ambassadors trained and visible for the release of the findings of the Respect. Now. Always. campaign survey in August 2017.

The campaign aligns with one of the key strategies of the USC Student Engagement and Retention Blueprint 2017-2020 (Nelson, 2016) - to 'enable support for learning - intentional, proactive, timely access to life and learning support'; and the key initiative to 'strategically extend and enhance peer to peer networking and learning'.

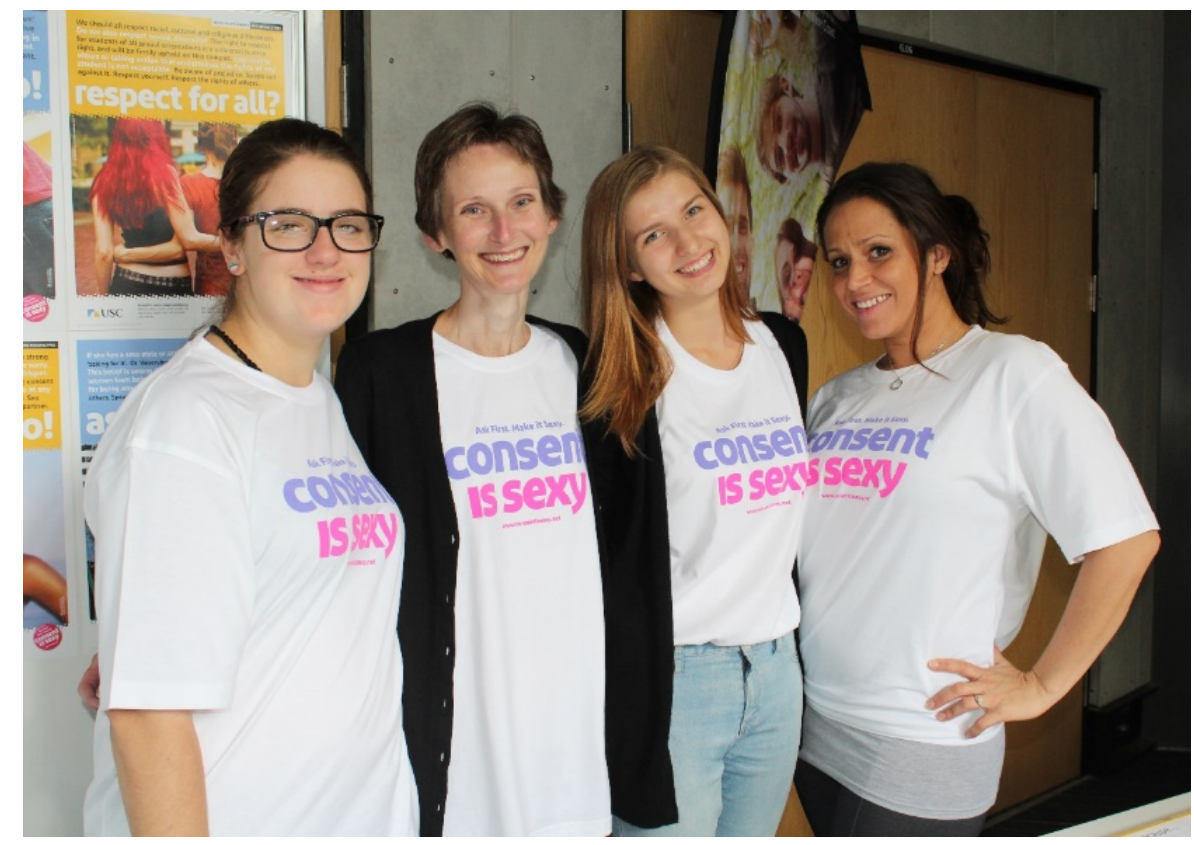

\section{Rationale}

Consent training is one of the 'good practice responses' recommended in the 'On Safe Ground' Strengthening Australian university responses to sexual assault and harassment' good practice guide developed by the Australian Human Rights Centre at UNSW (Durback \& Keith, 2017). The guide recommends consent training should be included "as a part of any university sexual violence prevention framework" (Durback \& Keith, p. 105).

Findings of the RNA survey showed $54 \%$ of the USC respondents reported being sexually harassed in 2016 (Australian Human Rights Commission 2017). Furthermore, 60.4\% knew little to nothing about 'where to go within the University to make a complaint about sexual abuse' (AHRC 2017). The training of CIS ambassadors seeks to address these issues by giving the ambassadors the skills and confidence to provide peer to peer support and promoting the prevention, support and report services for sexual harassment and assault provided by USC Student Wellbeing.

\section{Campaign objective}

The aim of the CIS campaign is to increase USC students' interest and understanding of the principles and practice of respect, consent and open discussion. It emphasises positive sexual behaviours, through increased knowledge and positive attitudes towards sexual consent. The expected outcomes of the CIS campaign were for students to be more informed about their sexual rights and more confident at negotiating boundaries and resolving differences in their intimate and other relationships through open, respectful communication. 


\section{Consent is Sexy ambassadors}

\section{Skills training workshop}

Student Wellbeing counselling and health promotion staff facilitated two-hour workshops for student volunteers to become Consent is Sexy Ambassadors. Volunteers for the CIS Ambassador training were recruited after responding to an expression of interest published in the student newsletter that is emailed to all students. Sixty-five students responded to this initial expression of interest and 50 of these students were trained as ambassadors in 2017.

Within the workshop students were introduced to the rationale of the campaign, including the RNA survey statistics on sexual assault and harassment on campuses. The ambassadors were encouraged to 'take ownership' of the campaign - to creatively collaborate, plan, organise and be 'out and about' on campus to deliver the consent based messages and hold the often-difficult conversations with student peers. Once trained, the CIS ambassadors promoted the campaign to raise awareness of sexual consent issues with their peers, encouraging open conversations about what consent is, how to ask for consent, and how you know you have or do not have consent. Promotional materials to assist the ambassadors included informational posters, leaflets, a website and Facebook content. The attention-grabbing CIS t-shirts made the ambassadors highly visible when promoting the campaign around campus.

\section{Walking the talk}

CIS ambassadors promoted the campaign whenever they wore their t-shirts around campus. After their training, the ambassadors were encouraged to wear the t-shirt as often as they liked on campus as an 'ice-breaker' or prompt to engage in conversation with their peers about consent. The other main promotion of the campaign has been at Student Wellbeing events. A major event for the CIS ambassadors was the release of the RNA results in October 2017. Consent is Sexy was one of three themes in USC's response to the release of the RNA results:

\section{1. \#webelieveyou}

\#webelieveyou is USC's message to educate students; firstly, that if students report an assault or harassment - USC will believe you. Secondly, to educate students on new USC processes for reporting sexual assault and harassment.

2. 'My Rights are not up for grabs' is a human-rights based response to the RNA survey release, in conjunction with the globalised 'Pussy Hat Project' and a community partnership with the Sunshine Coast 'Laurel Place Sexual Violence Counselling and Support'. Students are reminded to think about their own rights and those of others to not be assaulted or harassed.

\section{3. 'Consent is Sexy'}

On the day of the RNA survey release, students were very receptive to the Consent is Sexy Ambassadors. Upward of 500 students were reached with our messages. Both students and ambassadors reported the importance of the messages and the positive impact it had on them, and that these messages were backed by the University. 

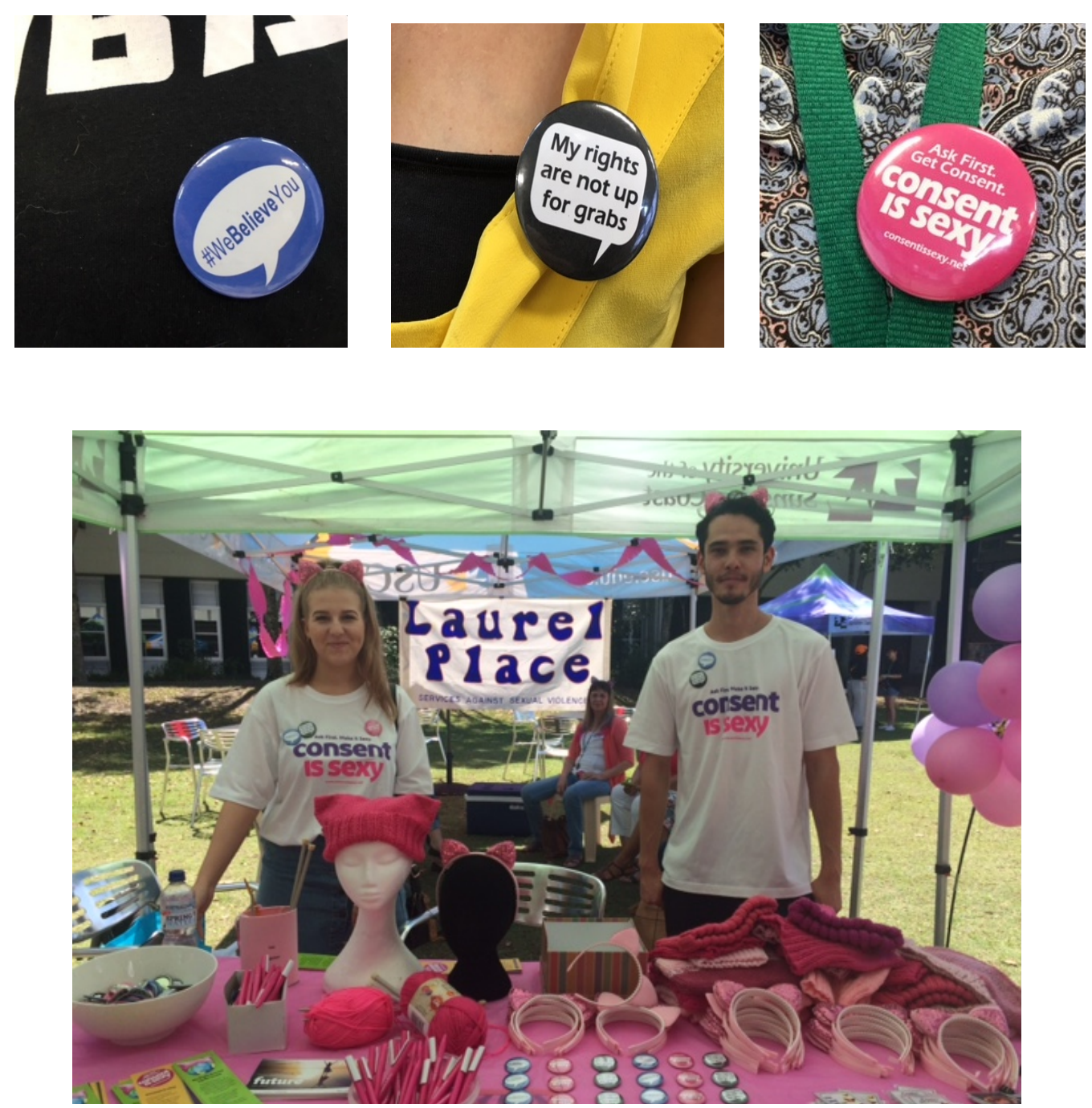

\section{Evaluation of the CIS Ambassador training workshop}

A self-reporting pre-and post-questionnaire was designed and administered to workshop volunteers by USC public health students as part of a curriculum based assessment piece. The public health students focused the evaluation on process (exposure, participation, delivery \& context) and impact (attitudes, beliefs \& knowledge) variables.

\section{Findings from the evaluation of the first cohort of ambassadors}

\section{Key process evaluation findings}

Training was delivered to 16 USC students ( $88 \%$ female, $12 \%$ male), average age of 24 years. Most participants were satisfied with the workshop; $63 \%$ reported a great overall impression, $31 \%$ a good overall impression, and $6 \%$ an okay overall impression. The majority of participants felt that the campaign is balanced and speaks equally to both men and women; $81 \%$ yes, $12.5 \%$ no, and one as 'somewhere in the middle'.

When asked whether there were any important issues not covered by the campaign, 75\% reported no, and $25 \%$ yes. Issues participants reported not being covered were 'homosexuality', 'changing minds', and 'rape reporting'. All of the workshop participants agreed that the Consent is Sexy campaign will create more awareness about issues of sexual respect and consent. 


\section{Key impact evaluation findings}

The workshop participants' attitude toward sexual consent and respect was assessed by asking: "How comfortable would you feel engaging in open discussion with your peers about sexual consent and respect?"; $75 \%$ of volunteers reported being 'very comfortable' pre-workshop compared to $81 \%$ post-workshop; $25 \%$ reported being somewhat comfortable pre-workshop compared to $19 \%$ post-workshop.

Participants' beliefs about sexual respect was measured by asking volunteers to rate their response to the question: "I believe sexual respect is"; $100 \%$ of volunteers believed that sexual respect was very important pre- and post-workshop.

Participants' knowledge about sexual respect and consent was measured by asking volunteers to rate their knowledge about the following: What is/isn't sexual respect? What is/isn't sexual consent?"

- Pre-workshop, 38\% rated their knowledge about sexual respect as very good; $44 \%$ as good and $18 \%$ as not sure; post workshop $75 \%$ very good and $25 \%$ good.

- Pre-workshop, 70\% rated their knowledge about sexual consent as very good and 30\% as good, compared to $81 \%$ and $19 \%$ respectively post workshop.

The post-workshop evaluation results indicated the training prepared the ambassadors with the knowledge and confidence to engage with other students in frank conversations about sexual consent.

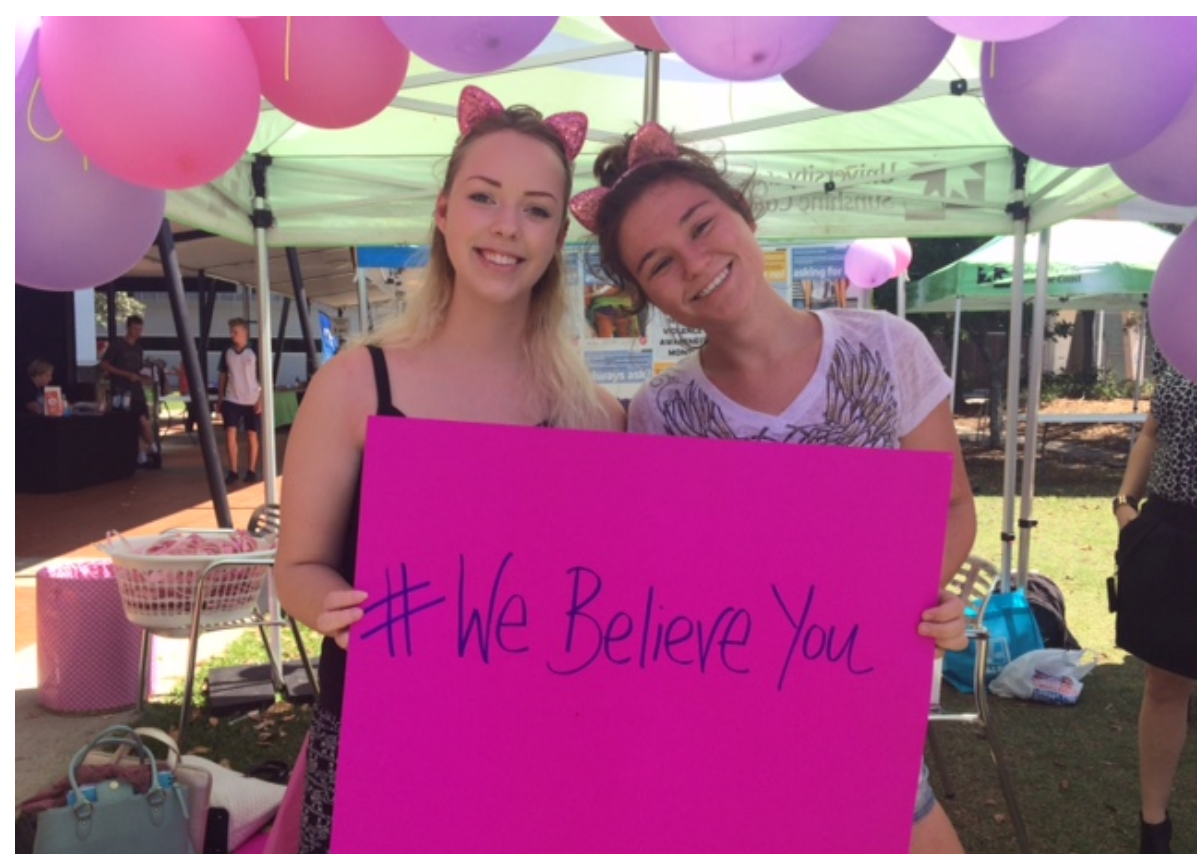

\section{Recommendations/future directions}

Feedback from the participants of the CIS ambassador training was that ambassadors were most concerned about how an ambassador should respond if a student discloses they have been a victim of sexual abuse. It is recommended that alongside any sort of peer to peer consent/sexual assault awareness campaigns should be 'responding to disclosures' training as well. In response to this recommendation, Student Wellbeing provided 'responding to disclosures of sexual assault/harassment' training. This consisted of a mixture of communication and counselling skills 
alongside education on university policy. This additional training was reported to ease the anxiety of ambassadors before going into the field to engage with students.

The ambassadors provided feedback suggesting positive interactions with students who understand the purpose of the campaign and the importance of highlighting and informing students about consent. Informal evaluation of the campaign's reach was conducted by collating statistics on the number of flyers and other campaign materials handed out by ambassadors to students. A formal evaluation of the campaign is planned for 2018.

To extend the reach of consent training, in 2018 USC will introduce the Consent Matters program: "an online course to help students understand sexual consent and promote positive change in the university community" (www.epigeum.com). The course will be available to all students as an embedded online Blackboard course. USC staff will also be encouraged to complete the training. The online training will complement the face-to-face interactions on campus with CIS ambassadors, posters and other campaign materials. The online Consent Matters training will be promoted at Orientation Week and in lectures during the first few weeks of the semester. The CIS ambassadors and student groups will also promote Consent Matters to encourage their peers to complete the online training. Student Wellbeing will monitor the uptake of the training and continue to consult with student representatives on opportunities to promote the training and increase uptake. 


\section{References}

Australian Human Rights Commission (2017). Change the course: National report on sexual assault and sexual harassment at Australian universities. Sydney: AHRC.

Durback, A., \& Keith, K. (2017). On Safe Ground: Strengthening Australian university responses to sexual assault and harassment. Sydney: UNSW Australian Human Rights Centre.

Nelson, K. (2016). USC student engagement \& retention blueprint 2017-2020. University of the Sunshine Coast, Sippy Downs.

The authors may be contacted via:

ozzyally@gmail.com

\section{Please cite this article as:}

Wills, A. \& Duncan, D. (2018). Consent is sexy when it is peer to peer. Journal of the Australian and New Zealand Student Services Association, (26)1, 64-70. https://doi.org.10.30688/janzssa.2018.01 